\title{
EL MOVIMIENTO SALAFISTA MODERNO Y LA SHARÍA ${ }^{1}$
} The modern salafist movement and the Shari'a

Brahim AGUIZOUL

Universidad de Granada

aguizoul1989@gmail.com

http://orcid.org/0000-0002-3313-5142

Recibido:09/07/2020. Revisado y aceptado para publicación: 04/12/2020

Para citar este artículo: Brahim AGUIZOUL (2020): "El movimiento salafista moderno y la sharía" en Revista de Estudios Internacionales Mediterráneos, 29, pp. 52-71.

Para acceder a este artículo: https://doi.org/10.15366/reim2020.29.006

\section{Resumen}

El presente artículo pretende abordar los grandes elementos que están detrás de la definición de sharía por parte de algunos movimientos islamistas. Trataremos de revelar los factores contextuales que subyacen detrás de esta definición y presentaremos las principales características del cambio anhelado para este concepto. Para ello, analizaremos el caso de los movimientos salafistas modernos.

Palabras clave: Movimientos salafistas modernos/Sharía/Renovación/

\section{Abstract}

This article seeks to address how the concept of the Shari'a is defined by different Islamic forces. We will try to reveal the contextual factors behind this definition, and present the main characteristics of this concept's long-awaited change. To this end, we will analyse the case of modern Salafist movements.

Keywords: Modern salafist movements/Shari'a/ renewal/

\section{Introducción}

Este estudio tiene como propósito investigar cuáles son los grandes elementos que están detrás de la definición de la sharía por parte de los movimientos salafistas modernos analizando varios aspectos que han sido influidos por esta definición y observando los contextos de producción del concepto. Asimismo, tiene como objetivo confirmar varios enfoques fundamentales cuya asimilación puede contribuir a ampliar la órbita del concepto de forma que agrupe diferentes

\footnotetext{
${ }^{1}$ Traducción del árabe de Luis Serrano Lora
} 
dimensiones de la civilización, esto es, abordar el cambio anhelado en "el paradigma islámico".

La problemática principal de este estudio se concentra en el marco de las preguntas: ¿Cómo podemos entender la sharía según los movimientos salafistas modernos? ¿Cómo podemos comprender el desarrollo semántico de este concepto? ¿En qué contextos se ha producido este desarrollo? ¿Cómo se podría entender positivamente este concepto teniendo en cuenta el desafío que supone la realidad contemporánea?

Partimos del hecho de que los antecedentes en que se basan los movimientos salafistas modernos no son sino una reacción a los efectos de la "modernización formal" que nace del seno de la ocupación extranjera y su prolongación en las políticas del Estado-Nación y sus proyectos de desarrollo. Es decir, estos antecedentes solamente expresan un mecanismo para defender la identidad, dado que están producidos por los movimientos salafistas y son producto de un contexto sociológico y antropológico caracterizado por la existencia de apuestas hegemónicas de fuerzas basadas en el control político y económico. Estos antecedentes en los que se basan están, en resumen, cargados de prejuicios al ser la sharía la senda de Dios a través de la historia, lo que es una reacción dotada de una dimensión identitaria basada en una memoria y una historia idealizadas e imaginadas y que poseen antecedentes políticos, económicos, sociales y epistemológicos.

Según esta hipótesis, la sharía en el imaginario de los movimientos salafistas modernos es un supuesto preparado de antemano ${ }^{2}$ y no una jurisprudencia que exige la búsqueda de la comprensión y la revelación permanentes.

\section{Antecedentes y metodología}

Trataremos de realizar una revisión de la literatura científica que estudia y analiza el "fenómeno islamista" en general ${ }^{3}$ desde un punto de vista sociológico. Del mismo modo, realizaremos una lectura crítica de estos intentos utilizándolos para comprender el objeto del estudio y análisis.

Cabe destacar que el "fenómeno islamista" ha sido objeto de controversia entre los investigadores quienes tienen múltiples opiniones al respecto. Esto se debe a las diferencias en su formación y a los marcos teóricos utilizados en sus respectivas interpretaciones y aproximaciones a este concepto.

De forma general podemos interpretar este fenómeno a través de tres enfoques fundamentales:

\section{El enfoque culturalista}

Este enfoque intenta explicar el fenómeno islamista y el ascenso de sus movimientos en la escena social desde un punto de vista basado en factores culturales.

En esta tendencia pueden enmarcarse los escritos del académico francés Gilles Kepel (Kepel, 1992 y 1995). Aunque no excluye otros factores en la interpretación de este fenómeno, su

\footnotetext{
${ }^{2}$ Véase el estudio de Aboullouz, Abdel Hakim (2009): Al-harakat al-salafiya fi-l-Maghreb (1971-2004). Bahz antropoloyi wa socioloyi (Los movimientos salafistas en Marruecos. Una investigación socio-antropológica). Beirut, Markaz Dirasat al-wahda al-arabiya, pp. 71, 209.

${ }^{3}$ Estamos hablando sobre un fenómeno heterogéneo (diferentes movimientos) que es, hoy en día, uno de los componentes de las sociedades arabo-islámicas. Aquí se usa el concepto de "el fenómeno islamista" para referirse a lo que une entre los diferentes componentes de este fenómeno, ya que la diferencia en los marcos referenciales, las actitudes y las maneras de entender la realidad, las maneras de actuar y los retos anhelados no pueden negar la estructura común de estos diferentes movimientos.
}

REIM № 29 (diciembre 2020) ISSN: $1887-4460$ 
aproximación se centra en el "problema subjetivo" que sufren los movimientos islamistas en general, ya que sus bases ideológicas siguen estando vinculadas al islam "tradicional", es decir, el islam de los textos fijados y que son difíciles de renovar y acompasar con la dinámica de la vida humana. Kepel lleva hasta el extremo su cuestionamiento del fenómeno: su crítica no solamente está dirigida a los movimientos islamistas, sino que se extrapola a un nivel general desde donde entiende que el problema no pertenece exclusivamente a los movimientos islamistas, sino también al marco de referencia del que se nutren estos movimientos: el pensamiento islámico en su conjunto, que entiende que está situado en el lado opuesto a los valores y convicciones del paradigma moderno.

Además, Kepel considera que el pensamiento islámico ha experimentado un giro notable hacia el radicalismo. Por consiguiente, este fenómeno solamente puede ser comprendido a través del factor cultural, esto es, la estructura nodal en el pensamiento islámico que implica una carga dogmática y que está construida sobre una posición excluyente.

En este mismo sentido, aunque con un contenido diferente, otros investigadores argumentan, al tratar de comprender el "fenómeno islamista", que este indica, probablemente, una protesta "cultural" contra el intento de imponer un nuevo estilo de vida y una forma determinada de pensar. Las aceleradas transformaciones que el mundo todavía conoce gracias a los cambios coordinados a nivel económico, social y cultural y todo lo que implican estas transformaciones desde el punto de vista cultural han provocado que diferentes identidades se tambaleen y, por consiguiente, han dado lugar a la búsqueda de una nueva posición desde la que poder autoafirmarse y ratificarse (Rouadija, 1990).

En este sentido, la expresión religiosa se convierte en el refugio que otorga al sujeto social un significado para su existencia, especialmente porque los vínculos tradicionales de la "sociedad local" se dirigen progresivamente hacia la desaparición, lo que introduce al sujeto en un estado de frustración y pérdida de sentido o lo que la sociología define como una crisis identitaria (Lamchichi, 1989).

\section{El enfoque materialista}

Además del enfoque cultural, que trata de presentar un modelo de interpretación del fenómeno islamista a través de sus factores culturales, existen otros puntos de vista que intentan abrirse un poco más a otros factores en la interpretación de este fenómeno.

Roy (Roy, 1996) considera que el traslado del radicalismo a la forma islámica solamente puede comprenderse a través del contexto de transformaciones que han vivido numerosos países de población mayoritariamente musulmana. Estas transformaciones económicas, políticas, sociales y culturales han tenido como resultado que algunos movimientos islamistas hayan adoptado el discurso radical e incluso la acción violenta.

Según Roy, el factor más relevante en la comprensión de este fenómeno es el cambio de patrones de producción dentro de estos países de mayoría musulmana: la difícil transición de una economía tradicional a una economía moderna en el ámbito del Estado moderno, con todas las transformaciones a nivel demográfico y el traslado de los individuos del campo a las ciudades. Todo esto se produce a raíz del fracaso del Estado-Nación que no ha logrado atender las nuevas necesidades y peticiones que exigía esta transición, un fracaso que se une en paralelo al fracaso del discurso de la izquierda que entusiasmaba a las masas con sus promesas de justicia social y de una vida digna.

Así pues, el resultado inevitable de la conjunción de estos factores es, según Roy, la aparición de discursos alternativos que intentan rechazar "lo que les ha sido impuesto", discursos dotados de un trasfondo religioso que obran como una manifestación de la disonancia existente entre los diferentes marcos de referencia. 
En esta misma línea, François Burgat (Burgat, 2001) atribuye el surgimiento del fenómeno islamista a factores materiales, aunque la aproximación de este último se distingue de las ideas de Kepel y Roy por poner en práctica una especie de reflexividad, es decir, una especie de autocrítica del pensamiento occidental al centrarse en el papel de la ocupación extranjera en la construcción de una respuesta islamista como reacción cultural a la disgregación de la sociedad.

Burgat critica a sus predecesores y los tacha de apoyarse en interpretaciones "preparadas" que no pueden acceder al núcleo del fenómeno. Así, Burgat considera que el "islam político" es la voz del sur oprimido, ya que los procesos de "domesticación y desarraigo cultural" practicados por la ocupación extranjera en nombre de la modernidad y la ilustración de forma directa o indirecta (los sistemas políticos que representan los intereses de Occidente) no han podido despejar la situación y crear una forma de vida globalizada. Por ello, considera que la única vía para entender este fenómeno, que expresa de forma profunda la conciencia colectiva de los pueblos de mayoría musulmana, es a través de esta cuestión política. En lugar de cuestionar las formas de las dinámicas sociales que se desprenden del seno de esta sociedad, Burgat cuestiona las formas políticas que han contribuido a su creación, por ello considera el fenómeno islamista como el tercer impulso dirigido a la liberación de la hegemonía occidental.

\section{El enfoque multidimensional}

Además de los enfoques anteriores, existen interesantes aportaciones de numerosos pensadores y sociólogos de origen árabe y musulmán. La mayoría de sus aproximaciones no escapan del alcance de los dos enfoques presentados previamente, donde se observa esta división entre quienes analizan el fenómeno a través de motivos "subjetivos" y quienes lo hacen a través de motivos "objetivos". Este círculo vicioso perdura debido a la ausencia de un enfoque que aúne lo subjetivo y lo objetivo.

Independientemente de las observaciones realizadas por Burgat sobre el enfoque cultural que traslada mensajes de dimensión política, la importancia de este enfoque radica en el interés por una cuestión fundamental, y es que, desde la modernidad, la humanidad (el modelo dominante) ha entrado en otra metodología de pensamiento y de criterios diferente al patrón tradicional, pues el mundo ha experimentado un proceso de cambios esenciales. Aquí radica la legitimidad de cuestionar el fenómeno a través de estos antecedentes. Abdallah Laroui considera que la metodología del pensamiento árabe se basa en la recuperación del pasado en una realidad completamente separada de él, es decir, se basa en la recuperación del tiempo cíclico y la marginación del tiempo dialéctico y dinámico (Laroui, 2006: 42).

Esta postura implica un aspecto importante a considerar, del mismo modo que la segunda postura, representada por Burgat, también implica otro aspecto a tener en cuenta. La defensa de "la lógica actual" puede entenderse como la defensa de las afirmaciones imperialistas que buscan estandarizar la vida de acuerdo a una única lógica y eliminando los diferentes sesgos cognitivos de otros pueblos, especialmente en sus visiones de la divinidad, el ser humano y la naturaleza. Asimismo, la defensa exclusiva del factor objetivo puede transmitir una actitud cómoda y tranquila hacia esta realidad "imitada", además de que puede indicar una sacralización del "yo" y la defensa de una supuesta particularidad. Nos encontramos frente a un estancamiento complejo que demanda un enfoque complejo que aúne lo subjetivo y lo objetivo, es decir, una visión que no dependa de un único factor en un marco de doble crítica (Al-Jatibi, 2000). 
Parece que el fenómeno religioso no es un rasgo inusual de la existencia humana, sino que este fenómeno sobrepasa lo sagrado y ha acompañado al ser humano y aún lo acompaña en su trayectoria y en su interacción con la naturaleza. No obstante, el desarrollo del ser humano y el descubrimiento de sus capacidades cognitivas y del uso de la razón a través de la historia han facilitado la formación de su conciencia en base a ciertos axiomas en los que se mezcla lo religioso con la superstición. En la época moderna, el ser humano se volvió más independiente en comparación con el pasado, sobre todo en sus percepciones del mundo, ya que adquirió una mayor autonomía y ambición por descifrar los secretos de este universo después de haber estado prisionero en el marco de las percepciones teológicas que ataban y restringían su libertad, su capacidad y su creatividad.

Por supuesto, estas percepciones no han sido únicamente exclusivas del contexto occidental, sino que es un fenómeno general que afecta a todas las religiones. La particularidad de la experiencia occidental radica en sus orígenes filosóficos y teológicos y en la forma de reacción violenta y de ruptura con las afirmaciones religiosas, lo que supone una profunda reacción contra la lógica aristotélica adoptada por la Iglesia para defender sus afirmaciones.

En lo referente a la experiencia islámica, lo presentado anteriormente es, hasta cierto punto, similar, puesto que la doctrina de la predestinación ${ }^{4}$ se ha deslizado en los textos islámicos desde una época temprana institucionalizándose durante la ocupación extranjera; aquí el problema de la subjetividad y la objetividad se superpone.

Sin embargo, si el objeto de esta investigación fuera abordar algunas de las deficiencias intelectuales que caracterizan a algunas de las fuerzas que toman el Islam como referencia, no significaría que este tratamiento de la cuestión tuviera que hacerse necesariamente a través de un enfoque "culturalista" (Gilles Kepel y Bernard Lewis), ya que este trasfondo se basa en observar los movimientos islamistas como una extensión esencial de un islam textual que se reproduce a sí mismo a través de la historia. El fenómeno en el marco de este estudio no se origina en un entorno cerrado, sino que es el resultado de un contexto social, cultural, político y económico que interviene en la producción de lo que es "subjetivo" y lo que es "objetivo", los factores "internos" y los factores "externos", los motivos micro y macro socio-antropológicos.

\section{Sobre los conceptos: salafismo moderno y sharía}

\section{El salafismo moderno}

El concepto del salafismo encierra múltiples connotaciones y significados. Esto se debe a que no expresa datos firmes y homogéneos, sino tendencias que, en la mayoría de las ocasiones, pueden ser variables, diferentes e incluso contradictorias, especialmente a nivel político (Abu Rumman, 2014: 33). El salafismo es un término amplio cuya definición difiere según los estudiosos y los investigadores, lo que implica que cada uno de ellos limita las connotaciones de este concepto basándose en sus criterios específicos y sus estrategias de investigación.

“Lingüísticamente, el término salafismo proviene de la raíz 'salaf' (antecesores) (...) y se refiere a los primeros tiempos del islam que son, según la creencia salafista, los que mejor representan la forma clara y correcta de comprender las disposiciones de la religión, de la legislación y de sus aplicaciones" (Abu Rumman, 2014: 33). Es, por lo tanto, "un intento de regresar a las fuentes de la religión, al islam original, a través del ejemplo de los sálaf, los primeros musulmanes, como una referencia para la comprensión del islam y su aplicación." (Rougier, 2008: 3).

\footnotetext{
${ }^{4}$ La doctrina de la predestinación es un compendio de pensamientos que sostiene que todo lo que sucede en la vida de la gente forma parte del plan de Dios, y, de ser así, no hay más opción que aceptar este destino. Esta doctrina surgió durante la toma del poder de Muawiya ben Abi Sufián, después de que éste se rebelara contra el modelo de consulta que había dominado antes de él, de este modo se podía justificar teológicamente la nueva realidad política.
} 
Así definido, el salafismo parece un intento de aferrarse a las viejas tendencias intelectuales y religiosas. Sin embargo, esta expresión tan general no contribuye a aclarar la definición del concepto. Así pues, ¿cómo podemos aproximarnos al salafismo y llegar al fondo de su significado?

\section{El salafismo y el fundamentalismo}

Algunos investigadores, como Gilles Kepel, utilizan el término fundamentalismo para referirse al salafismo en el contexto islámico ${ }^{5}$. El término fundamentalismo "se origina por primera vez en Occidente y, dentro de la cultura occidental, en Estados Unidos a principios del siglo XX, y hacía referencia a los fieles protestantes. El fundamentalismo es una descripción que se aplicó en aquel momento a los seguidores de la doctrina cristiana original para distinguirla de otros movimientos religiosos, puesto que creían en la perfección del Evangelio y luchaban contra los progresos de la modernidad (...), afirmando que la Biblia es científica en todos sus aspectos." (Al-Haydari, 2015: 270)

Abdel Wahab Al-Masiri señala en su trayectoria intelectual algunos de estos movimientos religiosos que rechazan el dinamismo de la historia o que la transforman en una simple leyenda finita. Entre esos movimientos se encuentra el denominado movimiento puritano, un grupo de protestantes radicales que tuvieron dificultades al tratar de permanecer dentro de la iglesia inglesa porque, según su percepción, esta no se alejaba lo suficiente del rito católico en las ceremonias, las imágenes y los ornamentos y pedían la "purificación" del culto cristiano de todos esos elementos internos que no se mencionan ni en el Antiguo ni en el Nuevo Testamento. "La conciencia puritana rechaza toda la historia cristiana e incluso toda visión de la historia en su conjunto, puesto que el retorno a la 'simplicidad primitiva' (un punto de quietud metafísica invariable e inmutable) se convierte en un deber para todos los individuos en cualquier momento o lugar". (Al-Masiri, 2015: 428).

\section{El salafismo y la imitación (taqlid)}

De acuerdo con lo anteriormente mencionado, podemos extraer el principio en el que se basa el salafismo y podemos resumir ese principio, que el salafismo comparte básicamente con los "fundamentalismos" en otros contextos, en el concepto denominado por Cioran como "el culto primitivo" ${ }^{6}$. Este concepto es prácticamente idéntico al concepto de "imitación" utilizado por Abdallah Laroui en tanto que es una metodología y una forma de pensamiento sobre el patrimonio, ya que se basa en la premisa de que la verdad existe en algún momento y lugar, alejándose totalmente del tiempo dialéctico y cambiante e invocando el tiempo cíclico y hostil hacia la dimensión histórica (Laroui, 2006: 42).

Los “sálaf" son los primeros referentes y los más fiables en la hermenéutica y la exégesis del texto, mientras que los "jalaf", es decir, sus sucesores, deben volver a estos con el objetivo de comprender sus acciones, comportarse correctamente y seguir su ejemplo. El salafismo es, por lo

\footnotetext{
${ }^{5}$ Quizás este concepto esté inspirado en el contexto cristiano para denotar que el fenómeno se produce en otro contexto donde hay un abuso sistemático. Esto se debe a que el fundamentalismo en el contexto islámico conlleva matices distintos a los que implica el contexto cristiano, puesto que el fundamentalista islámico es aquel individuo que lee la realidad y la renueva basándose en la sharía, esto es, el Corán y la Sunna, por lo que el fundamentalismo en la cultura islámica es un concepto que encierra connotaciones positivas. Véase Bishara, Azmi (2018): Fi-l-iyaba an alsual: ma al-salafiya? (Respondiendo a la pregunta ¿qué es el salafismo?) Beirut, Al-Markaz al-Arabi li-I-Abhaz waDirasat al-Siyasat, pp. 14-15.

${ }^{6}$ Cioran, E. M. (1986): Exercices d'admiration, Gallimard, p. 30, apud Shaygan, Daryuch (1993): Awham al-huwiya, Beirut, Dar al-saqi, p. 75.
} 
tanto, "una lectura fundamentalista y literal de los textos islámicos que decide situarse libremente en el lado opuesto a la interferencia de la razón en la comprensión del mensaje divino" (Rougier, 2008: 87). Asimismo, los salafistas "rompen con la denominada obediencia ciega de las escuelas jurídicas del islam suní que han configurado la historia religiosa de las sociedades musulmanas" (Rougier, 2008: 88). Esto significa que el enfoque salafista rechaza los intentos de estas escuelas de adaptar el islam normativo a las transformaciones impuestas por la realidad regida por las leyes del cambio, y, asimismo, rechaza esos nuevos interrogantes jamás planteados o respondidos pero que han sido impuestos por los nuevos contextos complejos.

Sobre esta base, Aboullouz considera su definición de salafismo en la investigación antropológica y sociológica sobre los movimientos salafistas en Marruecos como un indicador de un tipo de protesta contra las transformaciones producidas en dos de los niveles religiosos, la doctrina y el culto:

"Desde el punto de vista de la doctrina, el salafismo se preocupa por la reforma de la religión, con el objetivo de una racionalización metafísica y moral de las creencias sobre la vida. A nivel de culto, la tendencia salafista se interesa por la reforma de los rituales religiosos mediante la unificación de sus modelos, palabras, señales y procedimientos de forma que la religión conserve sus ritos originales y en contra de las recientes innovaciones." (Aboullouz, 2009: 11)

Esto significa que el salafismo "no es únicamente una protesta identitaria o estructural que permite conectar con los orígenes, sino también un proceso de aculturación, lo que significa un proceso de olvido de las culturas locales" (Roy, 2003: 14). El salafismo no está limitado y no se opone a la influencia o la multiplicidad cultural, sino que está determinado a través de la negación "cultural en un intento de emplazar el comportamiento cotidiano en el marco de lo lícito y lo ilícito, lo halal y lo haram" (Roy, 2003: 147)”.

En este sentido, el salafismo es la expresión del rechazo y el intento de exterminar las manifestaciones sociológicas y culturales del islam local en favor de un intento de difundir el islam textual que se muestra sociológicamente en "una tendencia religiosa que se manifiesta en movimientos de naturaleza sectaria que buscan garantizar la independencia respecto a las relaciones sociales dominantes" (Aboullouz, 2009: 11).

Las múltiples connotaciones del salafismo señaladas anteriormente, así como la diversidad de los movimientos salafistas (existen diferentes clasificaciones en función de diferentes variables: salafismo científico, tradicional, yihadista, reformista, nacionalista, etc.) se deben a las distintas estrategias y objetivos de cada uno de estos movimientos por separado. No obstante, a pesar de estas diferencias, varios investigadores consideran que el salafismo en general es "una corriente amplia que comparte un legado jurídico, intelectual y propagandístico y con él un compendio de libros, fetuas y teorización religiosa ininterrumpida a lo largo de los siglos" (Abu Rumman, 2014: 17). Frente a las diferencias en sus posturas políticas y las estrategias de cambio y de reforma, "los salafistas contemporáneos prácticamente coinciden en las líneas generales de la doctrina islámica y en determinadas referencias jurídicas e históricas" (Abu Rumman, 2014: 39). Independientemente de su postura dentro del tejido del movimiento salafista, los elementos comunes de los salafistas, generalmente, pueden reducirse a:

1. La gran preocupación por las diferenciaciones doctrinales, ya que afirman representar a los suníes, a las comunidades, a las sectas y a los partidarios del hadiz (dimensión doctrinal) (Roy, 2003: 137-138).

\footnotetext{
${ }^{7}$ Con negación "cultural" nos referimos a la negación de lo que la literatura antropológica y sociológica denomina el islam popular, basado en un conjunto de prácticas y rituales relacionados con las creencias "locales", es decir, arraigadas en el imaginario social y que han sido islamizadas: la visita de santuarios y tumbas (conocidos entre las tribus amazigh como "maaruf"), la sacralización de los santos... Véase: Eickelman, Dale (1991): Al islam fi-l-Magreb, Traducción de Mohamed Afif, Casablanca, Dar Tubqal li-I Nashr.
} 
2. El compromiso con una visión doctrinal unificada basada en la literalidad del texto que excluye la hermenéutica considerada como la búsqueda de todos los significados dentro del texto (dimensión epistemológica) (Gellner, 1992: 13-37).

3. Otorgar a la doctrina del monoteísmo un dominio central que la proyecte como una realidad cultural que está presente hasta en los más mínimos detalles (dimensión sociológica).

Por su parte, Geertz identifica el salafismo como "un intento activo de conformar una única ortodoxia para toda la población... Es una especie de énfasis sobre el establecimiento de una escuela jurídica que coincida con la doctrina, una revolución en las tradiciones religiosas clásicas, y la adopción del islam textual como modelo de todo pensamiento y actitud." (Geertz, 1993: 75)

\section{El salafismo en un contexto globalizado y estandarizado}

En otro nivel más amplio, y a partir de los modelos analíticos de algunos investigadores como Abdel Wahab Al-Masiri, el fenómeno salafista se entiende, al menos en su forma moderna (es decir, después de la ocupación extranjera y el establecimiento del Estado-Nación), como una expresión del rechazo a las nuevas transformaciones globales que han generado un nuevo orden mundial que busca estandarizar todos los aspectos de la vida de acuerdo con un único modelo que intenta exterminar y eliminar las múltiples formas de vida y de pensamiento, ya que "muchos pueblos del mundo han empezado a renunciar a su visión y sus prejuicios derivados de su realidad histórica, humana y existencial, para adoptar, consciente o inconscientemente, la visión de Occidente, mirándose a sí mismos desde el punto de vista occidental” (Al-Masiri, 2015: 460).

La hegemonía económica occidental crece en paralelo con la hegemonía cultural, ideológica y epistemológica "y desempeña un papel en el despertar de las fuerzas salafistas y fundamentalistas" (Tizini, 2008: 5-25).

El salafismo puede describirse como:

"La afirmación de la identidad como un mecanismo de defensa contra la globalización y un desafío contra la modernidad y las presiones del mundo contemporáneo, sus valores, cultura y actitudes establecidos que penetran en las sociedades, planteándoles interrogantes complejos y crueles (...) El salafismo es una imagen del otro repleta de connotaciones, símbolos y significados, pero antes de todo ello es una imagen del yo, considerada como la referencia por la cual se mide al otro" (Abu Rumman, 2014: 22).

Frente a la situación de inestabilidad social y económica como resultado del cambio de los modelos de producción y el mantenimiento de la independencia del aparato estatal, establecido por la ocupación extranjera y basada en el desequilibrio y la desigualdad, se opta por la autarquía para formar un mundo purificado e independiente del resto de las componentes de la sociedad.

En este sentido, el salafismo moderno son aquellos movimientos que pretenden garantizar una independencia acerca de las relaciones sociales dominantes y representar una respuesta al estado de confusión en que han estado sumidas las sociedades islámicas desde la ocupación extranjera y la implantación de sus instituciones, ideas, normas, representaciones, valores y modelos de percepción que son resultado de los contextos y las experiencias históricas de Occidente. Esta situación indica una crisis de identidad que afecta en primer lugar a las mentes de los sujetos sociales, ya que su naturaleza como individuos los ha integrado y construido socialmente a través de los modelos de educación que se nutren de este paradigma. Es decir, estos modelos dependen 
de referencias que son inconsistentes e incluso incompatibles y contradictorias en lo que respecta a su filosofía y su visión del universo, la vida, el ser humano o la naturaleza.

\section{La sharía}

En general, existen tres conceptos claves para comprender la imagen de la sharía que poseen los movimientos salafistas modernos:

\section{El gobierno divino}

Este concepto apareció por primera vez en los escritos de Abul Ala Maududi y Sayyid Qutb y deriva de algunas aleyas coránicas que reconocen que la decisión únicamente pertenece a Dios. Algunos investigadores, como Abul Qasem Hach Hamad (Hach Hamad, 2004: 39), opinan que el gobierno divino entendido por Maududi y Qutb, quienes han influido de forma decisiva en la conciencia religiosa islámica moderna, coloca el mundo en un marco de dicotomías entre Dios y el ser humano, entre la trascendencia y la naturaleza, entre la creencia y la ciencia, entre lo físico y lo metafísico. Esto era desconocido por los musulmanes de la época clásica que se caracterizaba, al menos a nivel jurídico, por la complementariedad entre El libro escrito (El Corán) y El libro percibido (la mente/razón). La jurisprudencia clásica no es sino una interacción humana con el libro escrito, mientras que los fundamentalistas (en sentido islámico) la han entendido como una interacción que permanece relativa como cualquier otra acción humana.

No obstante, en función de la representación estática de la jurisprudencia, "el derecho positivo" es rechazado en su totalidad por los movimientos salafistas ${ }^{8}$, al menos a nivel del discurso, lo que resulta comprensible si observamos las implicaciones de este término (el derecho positivo fue establecido en Occidente a causa del conflicto entre la religión y la razón que finalizó con la victoria de esta última y la subyugación de la primera), ya que conlleva la existencia de un "derecho no positivo" (trascendental), lo que contradice la experiencia del desarrollo histórico del islam (Ghalioun, 2007). Esta negación puede remontarse a otros factores que necesitan investigaciones antropológicas y no a la naturaleza de los contenidos per $\mathrm{se}^{9}$.

\section{El tauhid (el monoteísmo)}

Aboullouz considera que Muhámmad Ibn Abd al-Wahhab (fundador de la doctrina wahhabí) parte, en su formulación del concepto del monoteísmo, de una consideración jurídica que considera el tauhid, el monoteísmo absoluto, como la base de la religión islámica. Y sobre esta base, la sociedad debe reflejar esta idea. Si el tauhid es una característica fundamental de la divinidad, la sociedad también necesita materializar esta idea en su estructura, y el tauhid se traduce a nivel social a través de un conjunto de proyectos de unidad: unidad doctrinal, unidad jurídica, unidad comunitaria y unidad ritual (Aboullouz, 2009: 72).

Basándonos en esto, podemos observar cómo el tauhid se introduce desde el ámbito doctrinal para cubrir otros campos como la legislación, la política o el culto. Lo más relevante para nosotros,

\footnotetext{
${ }^{8}$ Posturas de numerosos movimientos salafistas en diferentes contextos: el movimiento Maghraouí en Marruecos, Ansar al-sharía en Túnez, el Partido Al-Nur en Egipto antes del golpe de estado militar contra Mursi (el programa electoral del partido en 2011)... Observamos además la preocupación de los distintos movimientos islamistas en este marco sobre sus textos doctrinales y de referencia, mientras el investigador lee una especie de deseo de "un ejemplo ideal" externo al derecho positivo establecido hace décadas.

${ }^{9}$ A este respecto, resulta de gran utilidad la lingüística contemporánea que señala que la adquisición del significado de los términos requiere un mayor interés sobre las dimensiones contextuales y discursivas (el contexto de habla y el contexto espacial). Por lo tanto, el término no está aislado de los contextos de su producción, y si la lengua oculta tanto como ilumina, prestar atención al contexto nos puede ayudar a revelar los significados y connotaciones ocultas por el lenguaje. En este sentido, el derecho divino que defienden los movimientos religiosos se transforma en el resultado de un contexto en el que las instituciones tradicionales, formadas a partir de la sharía, parecen expuestas a la desintegración y amenazadas por la eliminación debido a la modernización forzada. Esto no contradice el hecho de que el Estado, en el contexto divulgativo islámico, dirige a su pueblo de acuerdo a la tradición, como demostraremos a continuación.
} 
a través de este desplazamiento, es cómo el monoteísmo devocional tiene su contraparte en el pensamiento y en el discurso salafista.

Por lo tanto, la construcción de la idea del tauhid, en este sentido, genera ramificaciones que reconstruyen los diferentes temas conforme a la ideología salafista. Por ello, la afirmación central del pensamiento salafista es que el tauhid no solamente posee un contenido doctrinal, sino que también está cargado de referencias que cumplen numerosos objetivos. "Si Dios es uno y único, esto significa que solo existe una única manera apropiada de adorarlo" (Rougier, 2008: 235). Esto significa que, en el imaginario salafista, la unicidad de Dios debe estar relacionada con un único tipo de práctica religiosa y una única visión del universo.

El enfoque salafista "se presenta como la única forma legítima y verdadera de practicar el islam" (Rougier, 2008: 235), y se aprovecha de los contenidos doctrinales que posee el tauhid para proyectarlos en el modelo religioso salafista. Del mismo modo, como hemos señalado, combate la distancia existente entre la religión como una verdad divina otorgada, por un lado, y la religión como una adquisición humana gobernada por el principio de la relatividad, por otro. "La transformación de lo finito en infinito, de lo relativo en absoluto y de lo diverso en lo único no se lleva a cabo a través de la ciencia o de la fe, sino de la ideología, y más concretamente con un tipo determinado de ideología, el totalitarismo" (Bishara, 2013: 15).

Podemos observar y confirmar la importancia de que el tauhid, en el imaginario y la conciencia salafista, "no radica únicamente en la doctrina, sino que se apodera de lo 'religioso', haciéndolo surgir como una realidad cultural amplia" (Rougier, 2008: 238). Por lo tanto, la introducción de la idea del tauhid se convierte en una realidad cultural, es decir, ésta destaca y está activa en otros campos como la política, la cultura, etc. Si el tauhid es un modelo para todo pensamiento y actitud en diversos ámbitos, la democracia se convierte, en todas sus repercusiones de negociación y fragmentación del poder, en un señuelo y una desviación respecto a la ley divina.

\section{La herejía}

En ciertas fuentes islámicas, la herejía se define como el rechazo de todo lo que no es parte de la sharía, es decir, todo lo que no aparece mencionado en el marco del Corán y los hadices del profeta, las dos fuentes principales de la sharía.

Históricamente, observamos que la jurisprudencia islámica ha incorporado ciertos mecanismos para hacer frente a los nuevos fenómenos y acontecimientos. Las cuatro escuelas jurídicas se han esforzado por crear marcos teóricos que absorban las transformaciones urgentes sobre una sociedad cuya complejidad aumenta con el paso del tiempo y con la entrada de nuevos espacios culturales bajo la bandera del islam. La jurisprudencia, en este sentido, es un intento complejo de una transformación social y cultural basada en la dualidad de la transmisión (textos de referencia) y la razón (los mecanismos mentales creados por la lógica islámica en la lectura de estos textos).

Actualmente, podemos observar cómo algunos "movimientos renacentistas", en general, y los movimientos salafistas en particular, tienden a oponerse a esta norma. El concepto de la herejía juega un papel central en el rechazo del presente y la declaración de erigirse en el lado contrario a sus valores y sus fundamentos. Sin embargo, debemos enfatizar que el rechazo siempre se centra en el nivel del discurso, mientras que en la práctica podemos observar la aceptación de los medios de la modernidad y un amplio uso de los mismos. Olivier Roy confirma que esos movimientos (Roy, 2003) no podrían haberse extendido sin la utilización de medios técnicos modernos. Por lo tanto, el concepto de la comunidad digital ha sido tallado para connotar que estos movimientos 
son una comunidad imaginada.

Podemos entender este comportamiento, es decir, la aceptación de los medios modernos y la demostración de sus valores basándonos en la contribución de la escuela funcional a la sociología. La perturbación de la estructura social (la anomia social, en el lenguaje de la escuela funcional), se vio sacudida por la modernización forzada que sufrieron las sociedades islámicas, lo que provocó la aparición de nuevas formas de adaptación dentro de ese nuevo patrón. Entre los patrones más importantes de esta adaptación, encontramos el "patrón ritual", es decir, algunos sujetos rechazan cumplir los nuevos objetivos y normas que rigen la sociedad y que son establecidos y determinados por las élites dominantes que controlan el capital material y simbólico, mientras aceptan e incluso emplean los medios existentes que penetraron en esta sociedad a través de esta modernización forzada.

Estos tres conceptos (el gobierno divino, el tauhid y la herejía) son tres elementos fundamentales en el entramado que organiza la imagen de los movimientos salafistas del concepto de sharía. Hemos demostrado que esta imagen se caracteriza, generalmente, por la difusión, ya que estos movimientos se producen como una forma de defensa identitaria debido a lo que la escuela funcional denomina anomia social, la cual penetra en la estructura social.

Por consiguiente, su lectura solo puede entenderse considerándola una reacción contra la fragmentación del mundo entre la transmisión y la razón en una clara amenaza a las bases de la sociedad civil basada en la superposición de ambos (Ghalioun, 2007). Sin embargo, las razones de esta fragmentación en el concepto de la sharía no se deben a una única razón "mecánica", sino probablemente a interacciones más complejas anteriores al colonialismo y a la fundación del Estado-Nación.

\section{Contextos de desarrollo del concepto sharía}

\section{La crisis de la ausencia de una "renovación cualitativa" o una "renovación permanente"}

Tomamos estos conceptos de dos intelectuales: el sudanés Abul Qasim Hach Hamad (Hach Hamad, 2004), y el marroquí Muhámmad Ábid al-Yabri (al-Yabri, 1996). A pesar de las diferencias en los intereses de ambos pensadores en cuanto al tema de estudio, la metodología utilizada y sus antecedentes teóricos, ambos se ocupan de la misma problemática: la crisis civilizacional en el contexto islámico. Estos dos pensadores tratan de abordar los elementos de esta crisis civilizacional de forma general. Por nuestra parte, nos serviremos de estos dos conceptos analíticamente, y dentro de los límites de lo relacionado con nuestro problema de investigación.

La ausencia de una "renovación cualitativa o permanente" beneficia a las sociedades musulmanas cuyas élites, aun diferentes entre sí, siguen siendo prisioneras de los contenidos jurídicos que surgieron como resultado de la interacción de las primeras generaciones con el marco referencial religioso (El Corán y la Sunna) y continúan lo producido en la época de la compilación del Hadiz (el siglo II y III de la Hégira, correspondientes al siglo VII y VIII después de Cristo) en el control y la proyección del pensamiento árabe e islámico, practicando por consiguiente una contramedida epistemológica para cada nueva interacción cualitativa que se desvía de la tradición heredada ${ }^{10}$. Esta idea se resume en la afirmación de que no es posible crear nada que no haya sido creado ya en el marco de la conciencia religiosa y su forma (al-Yabri, 2009a: 102).

La ausencia de este tipo de renovación, vinculada al contexto anterior a la colonización y la intervención extranjera, y que realmente comenzó de forma temprana con el ascenso de formas políticas autoritarias que impidieron la movilidad social y la libertad de pensamiento a largo plazo, ha causado un profundo impacto que va en paralelo con la intervención extranjera y la aparición del denominado choque de la modernidad que ha demostrado la profundidad de esta

\footnotetext{
${ }^{10}$ Para más información, véase la tetralogía de al-Yabri sobre la crítica del pensamiento árabe, y los escritos de Mohammed Arkoun sobre la crítica del pensamiento islámico.
} 
problemática. La primera interacción con estas referencias, de acuerdo con lo inferido en la lectura histórica e historicista, fue solamente una lectura condicionada del factor socioeconómico además del factor intelectual y cultural de aquel entonces.

El fenómeno de la Modernidad contribuyó a cambiar la relación del ser humano con su existencia. Esta transformación se produjo como resultado de las acumulaciones históricas que contribuyeron a realizar un cambio cualitativo en esta relación. El ser humano ha pasado, debido a esta transformación, a otro sistema de pensamiento basado en la dialéctica ${ }^{11}$, reemplazando a los sistemas de pensamiento tradicionales basados en lo que los estudios antropológicos denominan animismo y teología. La ausencia de una renovación cualitativa significa, en el fondo, la ausencia de un avance en esta importante transformación del sistema de pensamiento humano, tanto en la metodología (de la deducción a la inducción), como en los contenidos (del sujeto que se somete al sujeto que cuestiona). Es decir, la renovación cualitativa requiere una revisión del pensamiento sobre los avances contemporáneos que se observan a través de los mecanismos tradicionales y los contenidos utilizados en la premodernidad. Hablamos aquí sobre las posibilidades de una conciencia contemporánea que absorba las diferentes transformaciones de la conciencia tradicional que se ha quedado estancada y que supuestamente ha contribuido a impedir la renovación de la sharía y la ha alejado del ritmo de la historia.

Las dimensiones de esta discusión pueden aclararse, con respecto a la problemática de la sharía, en lo que al-Yuryani define de la siguiente manera:

"La religión y la comunidad religiosa son diferentes, y a la vez están unidas. La sharía que se obedece se denomina religión, la sharía que reúne se denomina comunidad, y la sharía que se toma como referencia se denomina escuela jurídica. La diferencia entre estos tres términos es que la religión se atribuye a Dios, el credo al Profeta y la jurisprudencia a los juristas" ${ }^{12}$.

Podemos deducir de las palabras de al-Yuryani que la religión está profundamente subyugada al proceso de desarrollo. Aquí, el concepto de sharía agrupa tres significados fundamentales:

-La sharía como religión en su dimensión absoluta, es decir, como centro de santidad que está por encima de las profundidades de las limitaciones de la historia. Al-Yabri señala en su crítica del "pensamiento político árabe" que uno de los obstáculos más importantes de este pensamiento es el resultado de no distinguir entre la doctrina como centro de santidad y la sharía como un intento de comprender y aproximarse a esa doctrina. Los huecos más importantes del "pensamiento árabe", según al-Yabri, radican en la transformación de la opinión en la fuente de la doctrina, lo que puede contribuir a reducir las áreas de la diferencia (al-Yabri, 2009b).

-La sharía como credo, es decir, como núcleo de la comunidad en general. La sharía funciona aquí en el marco del establecimiento de las tradiciones y las normas de la comunidad. La inspiración de la sharía como religión en este marco comienza por los intentos de institucionalizar la legitimidad sobre la comunidad, considerándola una entidad

\footnotetext{
${ }^{11}$ La dialéctica no se entiende aquí en un sentido hegeliano o marxista, basada en la contradicción interna, sino en el sentido que encontramos en la filosofía del no de Bachelard, donde la negación incluye lo negado, como si las matemáticas contemporáneas incluyeran las matemáticas de Euclides.

${ }^{12}$ Al-Yuryani, Ali ben Mohamed al-Sharif. (1981): Al-taarifat, Maktaba Lubnan, págs. 23 y 111, apud Ghalioun, Burhan. (2007): Naqd al-siyasa: al-daula wa-I-din, Casablanca, Al-Markaz Al-Thaqafi Al-Arabi, p. 428.
} 
específica y determinada. Sin embargo, el intento de institucionalizar la legitimidad no significa necesariamente que sea un intento "legal", teniendo en cuenta que se basa, fundamentalmente, en la costumbre y la tradición.

-La sharía como escuela, es decir, como un intento de formulación de una escuela jurídica que trabaje en la legislación los nuevos fenómenos basados en la evidencia legal del marco de referencia del Corán y la Sunna. Aquí debemos señalar que la formulación de esta escuela, a pesar de estar basada en la evidencia legal, no deja de estar siempre abierta a la superposición, puesto que, originalmente, es una acción civil basada en el principio de la relatividad que son susceptibles de superponerse. Este es el nivel que critica al-Yabri, quien considera que el "pensamiento árabe" se ha transformado en una sharía como religión, es decir, como centro de la santidad.

En base a estos fundamentos, podemos decir que la tríada de al-Yuryani en la delimitación de la sharía indica el desarrollo histórico de la religión del islam. Este desarrollo ha venido acompañado por un proceso de caracterización a través de la aparición del Estado en un anhelo por organizar las relaciones entre la gente. Con el surgimiento del Estado, el ichtihad y la elaboración de las leyes se realizó desde la sharía, ya que esta pasó a significar jurisprudencia sin perder sus dos primeros significados. No obstante, con el aumento de la necesidad de asegurar las fuentes de legitimidad de las autoridades gobernantes (sobre todo en el primer período de la época abasí), se produjo un uso exagerado de la sharía como ley y, por ende, la institucionalización de la naturaleza sagrada del poder político. El califa se convirtió en la sombra de Dios en la tierra y la sharía en la obediencia de la ley. (Ghalioun, 2007: 429).

En líneas generales, la ausencia de una renovación cualitativa es un factor fundamental en el estancamiento de la sharía y exige, fundamentalmente, la necesidad de prestar atención a este proceso a cuya formación ha contribuido el factor político en detrimento de las posibilidades de la acción histórica a través de la reducción de la sharía en el derecho como mecanismo de control y dominación. Sin embargo, a pesar de haber desempeñado una función central en la formación de este proceso, este factor político se ha mantenido como una influencia relativa dado que el concepto de Estado que se tenía en aquel entonces no es el mismo que el que tenemos ahora (es decir, el Estado totalitario que puede intervenir en todos los ámbitos de la sociedad), aunque a largo plazo contribuyó a la ya mencionada destrucción de las posibilidades de innovación y, por lo tanto, de la libertad de pensamiento. Pero la profundidad del "exilio del concepto de la sharía" no aparece de forma explícita hasta el impacto con la Modernidad, mediante el cual descubre la profundidad de la brecha entre el patrón civilizacional local y el patrón civilizacional externo. Además, el proceso de modernización forzosa crea una contradicción entre la construcción material de las sociedades mayoritariamente musulmanas y su construcción simbólica. ¿Cómo podemos entender esta contradicción?

\section{La obstaculización de la renovación cualitativa}

Si la ausencia de una renovación cualitativa expresa una crisis propia derivada del estancamiento del "pensamiento islámico" y la interrupción del ritmo dinámico de la historia, la obstaculización de esta renovación revela con ello ese acto objetivo que ha marginado el proceso de renovación desde dentro, algo que comenzó con los pioneros de la Nahda (Yamal al-Din al-Afgani, Muhámmad Abduh y Rashid Ridá) ${ }^{13}$. Este proceso comenzó como un ichtihad individual, especialmente por el impacto causado por la Modernidad. Esto condujo a un replanteamiento de la religión de acuerdo a nuevas reglas y mecanismos, pero no logró un cambio cualitativo en la conciencia islámica y en la estructura cultural en general debido al colonialismo cuyos "intereses"

\footnotetext{
${ }^{13}$ Los pioneros del salafismo reformista que es diferente del objeto de este estudio, el salafismo moderno en su sentido señalado arriba.
} 
se oponían a esta transformación y trató de anular objetivamente los efectos de ese ichtihad a través de sus políticas aplicadas, especialmente, en los asuntos religiosos.

La ocupación extranjera exportó el modelo de Estado-Nación a sus colonias, pero ese EstadoNación se formó de acuerdo a una lógica dual que combina la conservación del patrimonio histórico (especialmente las tradiciones que limitan cualquier posibilidad de crear y marginar los elementos de liberación en este mismo patrimonio) y la consagración de este patrimonio a través de mecanismos modernos, materiales y simbólicos ${ }^{14}$.

Precisamente podemos decir que los factores del despotismo y la opresión de los que se liberó Europa durante la época del Renacimiento trataron de aplicarse fuera de su marco geográfico si nos basamos en los estudios antropológicos y sociológicos empleados para comprender y controlar esas sociedades.

El concepto de Estado, en su sentido moderno, surge como una respuesta teórica y práctica a la proliferación de fenómenos de fragmentación en Europa encarnados en las guerras religiosas y sectarias. Por lo tanto, este concepto surgió para organizar el proceso de conflicto convirtiéndolo en un conflicto "civil" en el que las clases sociales reemplazan a las "identidades tradicionales" creando así mecanismos alternativos para gestionar el conflicto (las instituciones legislativas) y asegurar vías y salidas para las dinámicas sociales con el fin de tratar de integrar las diferentes fuerzas sociales y también de mantener el Estado como un agente procesal que planifica todo este proceso.

En cambio, el Estado surge en las colonias como un aparato funcional que desempeña funciones específicas que responden a intereses externos. Esta "dualidad" no deseaba alcanzar una transformación histórica y cultural en estas sociedades, sino una "modernización formal" que contribuyó a lo que se denomina el desarraigo cultural. En otro sentido, la "modernización formal" no significa que no se produzcan cambios culturales, sino que esos cambios culturales se producen en sentido negativo, empleándose sobre todo en el marco de la conservación de las bases del poder y las relaciones de poder entre los países, en primera instancia, y posteriormente entre los componentes sociales dentro de la misma entidad política.

Para poner estas ideas al servicio de la problemática estudiada es importante señalar la profundidad de la conexión entre la política religiosa seguida por las potencias coloniales y sus colonias y la política religiosa durante su independencia.

En el contexto marroquí, por ejemplo, el residente general Lyautey fue el arquitecto del "Marruecos moderno", quien aprovechó los estudios sociológicos en el marco de la consolidación del dominio francés sobre Marruecos y protegió "le vieux Maroc" (Alcantud, 2019: 255) combinando elementos tradicionales con otros modernos. Siendo precisos, Lyautey otorgó a la tradición una dimensión moderna contribuyendo a su difusión y consagración en lo más profundo de las estructuras de la sociedad. En lugar de enfocarse en la liberación de la autoridad de la época de su dimensión teológica, como sucedió en Europa y como dicta la lógica de la Modernidad, Lyautey institucionalizó una especie de teología sobre la autoridad, otorgándole mecanismos modernos para su difusión y perpetuación que se mantuvieron en el contexto de la independencia. De esta manera, el Majzén ${ }^{15}$ se fortaleció gracias al Protectorado y a su política

\footnotetext{
${ }^{14}$ Diversas instituciones sociales modernas que ya no son estrictamente locales han pasado a manos del Estado, un aparato mucho más penetrante: la escuela, la asamblea, el partido, la mezquita, los medios de comunicación...

${ }^{15}$ El nombre histórico del sistema político marroquí
} 
religiosa basada en el "Principado de los Creyentes" como una institución supraconstitucional que domina diferentes ámbitos y reproduce el juego político en general de acuerdo a fórmulas desiguales ${ }^{16}$. En este marco, Tozy observa que, a pesar de que la autoridad religiosa ocupa una posición importante en la estrategia del régimen político:

“No solamente enmarca los múltiples aspectos de la cultura política. El sistema está llamado a adaptarse a los avances actuales adoptando métodos y medios impuestos por la Modernidad y la modernización. La mención de conceptos novedosos e ideas de las culturas dominantes (democracia, derechos humanos, etc.) es un proceso que no puede realizarse sin distorsionar el significado original de dichos conceptos [...]. Este proceso refleja el deseo de hibridar estos conceptos y despojarlos de su contenido" (Tozy, 2001: 9).

Basándonos en esta idea, la obstaculización de la renovación cualitativa está vinculada a la estructura del estado moderno en este contexto, ya que es difícil hablar de esta renovación fuera del contexto de la libertad y en el marco de las restricciones que ejercen los regímenes políticos sobre la ciencia, los académicos y sobre el panorama intelectual en general. El problema es, por lo tanto, estructural e intrínseco a las relaciones enmarcadas en los diversos elementos del orden, lo que no se opone a la lectura histórica que establece que la historia moderna de estos países está experimentando una oscilación entre las fuerzas que aspiran a liberar al Estado de una estructura de retroceso y una fuerza que desea que permanezca en esta misma situación durante el mayor tiempo posible a través de la construcción de la sacralidad del estado y despojando su forma moderna de cualquier significado moderno.

Precisamente aquí, en la construcción de la sacralidad del Estado y su despojo de cualquier contenido moderno, radica el problema de la sharía, tal y como la entienden diferentes fuerzas religiosas. La mayoría de las entidades políticas, en el contexto divulgativo islámico, tienden a inventar una combinación de políticas económicas que han contribuido al desmantelamiento de las estructuras sociales tradicionales y de un marco ideológico que se basa en "tradiciones" religiosas y culturales que se remontan a un pasado lejano. En otro sentido, la modernización forzada ha impuesto sobre estas sociedades la lógica posterior a la revolución industrial en lo que respecta a sus fines materiales en un intento de controlar las contradicciones de esta nueva lógica a través de lecturas reduccionistas y dominantes de la religión, sirviéndose de esta lógica en la legitimación, por un lado y por otro desestabilizando a los movimientos religiosos modernos que se nutren de la fe para rechazar este novedoso sistema social híbrido, especialmente después de la dinámica que surgió a finales de los años setenta del pasado siglo tras la revolución iraní (Hmimnat, 2018).

La mayoría de estos movimientos han alzado lemas que demandan la aplicación de la sharía. Esta consigna expresa la marginación del sujeto social fruto de las políticas de estos países que han contribuido, como hemos señalado previamente, a la desestabilización y el desmantelamiento del sistema social tradicional con sus estructuras de solidaridad y su dimensión agrícola tradicional. Asimismo, expresa las aspiraciones y las esperanzas de las fuerzas sociales cuyos sujetos nacieron y crecieron en este contexto de deconstrucción. Por lo tanto, este lema tiene una forma religiosa, lo que puede entenderse en base al hecho de que las fuerzas sociales de dentro de la sociedad recurren a la religión como modo de protegerse de la modernidad forzada que privó a la sociedad de su estructura solidaria. Sin embargo, también puede expresar aspiraciones identitarias y esperanzas relacionadas con la forma del Estado y su naturaleza y el vehículo más fuerte para

\footnotetext{
${ }^{16}$ Abdellatif Aknouch estudia cómo la Constitución marroquí se compone de dos niveles: uno inferior, que normalmente se traduce en el Derecho Constitucional, considerado el conjunto de normas legales relacionadas con el juego parlamentario entre el Gobierno y el Parlamento que disfrutan de una relativa soberanía; y otro superior, que se traduce en el Derecho Califal y del sultán Príncipe de los Creyentes, obediencia, santidad... Sus disposiciones están relacionadas con el estatus político y religioso del monarca. Véase Aknouch, Abdellatif (1988): Al-sulta wa-l-muassasat al-siyasiya fi Magreb al-ams wa-l-yaum, Casablanca, Maktaba Profanus, 172.
} 
interpretar la demanda de aplicar la sharía podría radicar en el fracaso de la adaptación del Estado moderno al contexto divulgativo islámico, lo que se expresa en el hecho de que el derecho, en el "Estado islámico contemporáneo", se reduce en algunos contenidos e incluso pasa por alto otros de gran importancia, como la efectividad del sistema legislativo y la autonomía del sistema judicial. Es decir, sobre un determinado patrón de distribución y fragmentación del poder, el Estado no es quien se encarga de producir el contenido legal, sino que las fuerzas de la sociedad son quienes realmente exigen la producción de ese contenido a través de las instituciones legislativas que, supuestamente, encarnan el consenso de la sociedad. El Estado aquí no es un actor procesal que debe supervisar ese contenido legal, sino que debe garantizar su validez y el acceso a él. (Ghalioun, 2007).

El resultado es que la trayectoria de la "modernización formal" se dirige contra las conclusiones de este último párrafo. Así pues, es un obstáculo para el proceso de modernización real en lo que respecta la liberación de las fuentes del poder y de una posible dinámica para la interacción entre lo "local" y lo "universal" y, por lo tanto, es el vehículo más fuerte en la interpretación del surgimiento de la necesidad de aplicar la sharía por parte de los movimientos religiosos. La ausencia de una tradición ética y moral alternativa, tanto si la religión está separada de la política como si esta última controla a la primera, ha llevado a profundizar el papel de la religión en el ámbito público, y más concretamente en la política (la necesidad de la aplicación de sharía) “El Estado creado tras el corto periodo de alejamiento respecto a la religión ha vuelto a utilizarla de nuevo, no como un sistema ético que ordena la justicia, la equidad, la tolerancia y las buenas conductas y comportamientos, ni como una religión popular y tribal que crea su significado en la comunidad local, sino como un mecanismo para ejercer diversas funciones centradas fundamentalmente en la vigilancia y el control". (Bishara, 2018b: 319)

\section{El cambio anhelado}

El cambio anhelado en la determinación del concepto de la sharía por parte de los movimientos religiosos y salafistas en el contexto divulgativo islámico está vinculado a contextos "objetivos" y "subjetivos", al mismo tiempo que no está relacionado con determinadas revisiones reduccionistas. Estamos hablando de un cambio histórico, cultural y estructural en las sociedades de mayoría musulmana y en las relaciones internacionales basadas en el principio de la dominación, que puede no alcanzarse si el pensamiento animista y teológico continúan dirigiendo la conciencia religiosa de estas sociedades. Actualmente, existe una necesidad urgente de volver a interactuar con los textos de referencia mediante una conciencia contemporánea que contradiga los sistemas de pensamiento tradicionales. En general, podemos resumir las rutas de este cambio de la siguiente manera:

\section{La ruta positiva}

Esta ruta supone que la tendencia salafista revise sus tesis, sus axiomas y sus principios fundamentales. Sin embargo, estas revisiones pueden suponer la fusión del salafismo en la estructura social tanto a nivel de forma como de contenido, lo que significa que no será meramente un aspecto emergente de esta sociedad, sino que estará profundamente arraigada e imbuida de su cultura. Esta ruta supone un esfuerzo y una crítica importante a través de la cual el pensamiento salafista adquiere la capacidad de comprender la realidad en lugar de condenarla solamente. 
Sin embargo, este cambio también supone la existencia de transformaciones estructurales a nivel nacional y global. A nivel nacional, el "Estado" debe enfocarse en profundizar las reformas en lugar de ser una potencia dominante que se muestra hostil con su entorno y que "asesina" a las identidades locales en sus diversas formas, lo que impone la participación de diversas fuerzas intelectuales e ideológicas en la gestión del poder y la interacción con las diversas dinámicas sociales mediante una lógica de escucha, no excluyente, considerando que detrás de cada fenómeno hay uno o varios significados que deben ser bien percibidos. Esta lógica no se aplica a través de la aproximación tecnócrata que se sirve de las políticas públicas preparadas e incluso proyectadas de antemano. Por el contrario, es imprescindible abordar las necesidades de la sociedad en términos de un entendimiento que responda a las auténticas necesidades de esta sociedad, necesidades derivadas de las preocupaciones y los intereses de las personas. Por otro lado, este cambio también supone una cuestión central: la necesidad de neutralizar el Estado y afianzarlo como un actor procesal. Esto significa que las fuerzas sociales son quienes producen los contenidos jurídicos que enmarcan a la clase política a través de las instituciones legislativas que supuestamente desempeñan funciones reales $y$, por consiguiente, se pasa de una situación de conflicto sobre el Estado a una situación de conflicto dentro del Estado entre las diferentes visiones y percepciones sobre el modo de gestionar la sociedad.

Esta es la situación a nivel general. De forma particular, debido a las singularidades de la relación del Estado con lo religioso, el Estado debe abstenerse de entrometerse, controlar e influir negativamente en los asuntos religiosos.

Cuando hablamos de cambio estructural a nivel estatal no lo hacemos únicamente a nivel de los movimientos salafistas. Es una cuestión relacionada con el interrogante de la reforma o la renovación que otorga a la Modernidad otras posibles definiciones más allá de la producida por el concepto del Estado en el contexto occidental del Renacimiento y la llustración.

Esto nos lleva a hablar del contexto global, supuestamente asentado sobre esta base, y en paralelo a la dinámica interna anteriormente mencionada, así como al creciente número de "identidades" que reclaman su derecho a la riqueza material y simbólica, repartida de forma injusta por todo el mundo. Idealmente, las fuerzas dominantes habrían de retirarse de la lógica de la explotación y aceptar gradualmente un mundo multipolar, es decir, un mundo que acepta la dualidad entre lo general y lo particular. Esto significa una retirada de estas fuerzas de su interferencia injusta en los diferentes países y el respeto a su voluntad colectiva. Estamos hablando de la Modernidad humana en el sentido real de la palabra, es decir, una Modernidad que respeta y apoya el pluralismo, las diferencias y la diversidad.

\section{La ruta negativa}

A diferencia de la primera ruta, el salafismo puede enfocarse a una mayor compartimentación, automarginación y persistencia en un discurso extremista que rechaza cualquier consenso, en caso de que el sujeto salafista fracasase, en primer lugar, en la autocrítica y en el diagnóstico de lo que está "muerto" en su patrimonio (lo que no puede producirse sin una apertura crítica a las humanidades y las ciencias sociales), y también en caso de que las circunstancias permanezcan inalterables tanto a nivel local como global.

La autocrítica es, precisamente, lo que se requiere de los movimientos salafistas. Ahora bien, esto seguirá siendo una mera ilusión, o como mínimo, una cuestión estéril, puesto que los textos religiosos establecen el mismo orden mental tradicional y cerrado que margina la eficiencia humana y la capacidad de la mente para generar significados renovadores de las referencias religiosas. La liberación de la comprensión de la autoridad "tradicional" demanda una comprensión de la relación complementaria entre las aleyas legisladoras (las ciencias religiosas), las aleyas humanas (las ciencias humanas), las aleyas científicas (las ciencias experimentales) en el 
marco de una metodología epistemológica que contradice la predestinación teológica y el positivismo.

\section{Conclusiones}

La sharía, entonces, es un modelo para el descubrimiento y el desarrollo. La universalidad del "Libro" puede significar que este "Libro" es una llamada a la conciencia de un movimiento existente en el mundo social y humano y en el universo y la naturaleza.

Este llamamiento no puede interactuar con la sharía como si se tratara de derecho positivo o códigos jurídicos en el sentido contemporáneo. La interacción con el Corán en la extracción de conceptos como "gobierno divino" es una interacción regulada por el contexto de contacto con los conceptos construidos por el Estado moderno, lo que produce reacciones que reducen la sharía a limitaciones fijas.

Lo invariable en la sharía, según la filosofía religiosa moderna, es su marco moral que recuerda al sujeto su papel como ser humano, distinto de la condición animal y el comportamiento primitivo que niega cualquier límite o valor tanto morales como sociales.

Basándonos en esto, y considerando el cambio como una característica más de la existencia humana, la sharía debe ser redefinida como un intento de comprender los propósitos de la ley en cualquier contexto, debiendo entenderse la ley de acuerdo a esos movimientos en el mundo humano y en el mundo natural. Este es el significado más probable del ichtihad, la interpretación de las fuentes del derecho islámico.

\section{Referencias}

ABU RUMMAN, Muhammád (2014): Ana salafí. Bahz fi-l-huwiya al-waqaiya wa-l-mutajayyala lada-I-salafiyin (Yo soy salafí. Una investigación sobre la identidad real e imaginada de los salafistas), Omán, Friedrich Ebert Stiftung.

ABOULLOUZ, Abdel Hakim (2009): Al-harakat al-salafiya fi-l-Magreb (1971-2004). Bahz antropoloyi socioloyi (Los movimientos salafístas en Marruecos. Una investigación socio-antropológica), Beirut, Markaz Dirasat al-Wahda al-Arabiya.

AKNUSH, Abdel Latif (1988): Al-sulta wa-I-muassasat al-siyasiya fi Magreb al-ams wa-l-yaum (El poder y la institución política en el Marrurecos de ayer y de hoy), Casablanca, Maktaba Profanus.

BISHARA, Azmi (2013): Al-Din wa-I-almaniyya fi siyaq tariji (La religión y el laicismo en un contexto histórico), Beirut, Al-Markaz al-Arabi li-I-Abhaz wa-Dirasa al-Siyasat.

--- (2018a): Fi-l-iyaba an al-sual: ma al-salafiya? (Respondiendo a la pregunta ¿qué es la salafiya?) Beirut, Al-Markaz al-Arabi li-I-Abhaz wa-Dirasa al-Siyasat.

--- (2018b): Al-taifa, al-taifiya, al-tawaif al-mutajayyila (Taifa, sectarismo y taifas imaginarias) Beirut, Al-Markaz al- Arabi li-l-Abhaz wa-Dirasa al-Siyasat.

BURGAT, François (2001): Al-islam al-siyasi. Saut al-yanub (El islam político. La voz del sur) (Traducción de Lorin Zakri), El Cairo, Dar al-Alam al-Thalith. 
EICKELMAN, Dale (1991): Al-Islam fi-l-Magreb (El islam en Marruecos) (Traducción de Mohamed Afif), Casablanca, Dar Tubqal li-I-Nashr.

GEERTZ, Clifford (1993): Al-Islam min wuchha nadar ilm al-inasa. Al-tatawwur al-dini fi-I-Magreb wa-Indunisia (Observando el islam. Desarrollo religioso en Marruecos e Indonesia) Beirut, Dar alMuntajab al-Arabi.

GELLNER, Ernest (1992): Posmodernismo, razón y religión, Barcelona, Paidós Ibérica.

GHALIOUN, Burhan (2007): Naqd al siyasa: al-daula wa-l-din (Crítica de la política: el Estado y la religión) Casablanca, Al-Markaz Al-Thaqafi Al-Arabi.

GONZÁLEZ ALCANTUD, José Antonio (2019): Historia colonial de Marruecos (1864-1961), Almuzara.

HACH HAMAD, Abul Qasim (2004): Al-Azma al-fikriya wa-l-hadariya fi-l-waqia al-arabi al-rahen (Crisis ideológica y civilizacional en el mundo árabe actual) Beirut, Dar al-Hadi.

HAYDARI, Ibrahim al- (2010): Susiuluyia al-unf wa-l-irhab (Sociología de la violencia y el terrorismo) Beirut, Dar al-Saqi.

HMIMNAT, Salim (2018): Al-siyasa al-diniya bi-l-Magreb (1984-2002). Usuliya al-daula wa-ikrahat al-tahdiz al-sultawi (Política religiosa en Marruecos 1984-2002. Fundamentalismo de Estado y coerciones de la modernización autoritaria) Casablanca, Dar Afriqia al-Sharq.

JATIBI, Abdel Kabir al- (2000): Al-naqd al-muzdawich (La doble crítica) Rabat, Manshurat Ukaz.

KEPEL, Gilles (1992): Yaum Alah. Al-harakat al-usuliya al-muasira fi-l-diyanat al-thalath (El día de Dios. Los movimientos fundamentalistas contemporáneos en las tres religiones monoteístas) (Traducción de Nasir Marwa) Casablanca, Dar Qurtuba li-I-Nashr wa-I-Tauthiq wa-I- Abhaz.

--- (1995): Les politiques de Dieu, París, Editions du seuil.

LAMCHICHI, A. (1989): Islam et contestation au Maghreb, París, L'Harmattan.

LAROUI, Abdallah (2006): Al-arab wa-l-fikr al-tariji (Los árabes y el pensamiento histórico) Casablanca, Al-Markaz Al-Thaqafi Al-Arabi.

MASIRI, Abdel Wahab al- (2013): Rihlati al-fikriya fi-l-budur wa-l-yudur wa-l-zamar (Mi viaje ideológico. Semillas, raíces y frutos) El Cairo, Dar al-Shuruq.

ROUADIJA, A. (1990): Les frères et la mosquée: enquête sur le mouvement islamiste en Algérie, París, Karthala. https://doi.org/10.3917/kart.roua.1990.01

ROUGIER, Bernard (2008): Qu'est-ce que le salafisme?, París, PUF. https://doi.org/10.3917/puf.rougi.2008.01

ROY, Olivier (1996): Genealogía del is/amismo, Barcelona, Ediciones Bellaterra.

--- (2003): El islam mundializado, Barcelona, Ediciones Bellaterra.

SHAYEGAN, Daryush (1993): Awham al-huwiya (Les illusions d'identité) (Traducción de Mohamad Ali Mokaled), Beirut, Dar al- saqi.

TIZINI, Tayeb (abril-junio 2008): "Mafhum al-turath al-alami madjal bi-ittiyah al-taasis" (EI concepto de patrimonio mundial. En vías de institucionalización), Alam al-fikr, no 4, vol. 36, pp. 525. 
TOZY, Mohamed (2001): Al-malakiya wa-l-islam al-siyasi fi-l-Magreb (La monarquía y el islam político en Marruecos) (Traducción de Mohamed Hatimi) Casablanca, Nashr al- Fanak.

YABRI, Muhámmad Ábid al- (1996): Al-din wa-I-daula wa-tatbiq al-sharía (Religión, Estado y aplicación de la sharía) Beirut, Markaz Dirasat al-Wahda al-Arabiya.

--- (2009a): Takwin al-aql al-arabi (La formación de la razón árabe) Beirut, Markaz Dirasat alWahda al-Arabiya.

--- (2009b): Al-aql al-siyasi al-arabi. Muhaddadatuhu wa-tachliyatuhu (La razón política árabe. Limitaciones y manifestaciones) Beirut, Markaz Dirasat al-Wahda al-Arabiya. 